\title{
Science in acts / "Mathematics and formalism" by Jean Cavailles and Georges Canguilhem; review Alonzo Church.
}

Camille Akmut

\begin{abstract}
Translation of "Mathematiques et formalisme" by Jean Cavailles and Georges Canguilhem; with introductions by two. Including a 1950 review by Alonzo Church.
\end{abstract}




\section{Introduction : a forgotten hero of logic and computer science}

Jean Cavailles has a definite place within the philosophy and history of computer science.

This is in addition to mathematics, where his situation is already guaranteed, and where he continues to be an object of regular attention.

This place he has won based on his writings, like "The School of Vienna at Prague" :

As early as after the War, or at the latest then, his work's significance had not escaped the wider international community of computer scientists - this was before "computer scientists" carried such a name and before they could conceive of themselves in terms of a separate, fixed scientific identity, let alone organized academic group.

In 1950, Alonzo Church wrote a review for "Mathematiques et formalisme", which the reader will find here in a first or new translation under the title "Mathematics and formalism" (Science in acts).

Cavailles' influence on later generations of philosophers continues to be seen everywhere in this text :

When reading Foucault's flamboyant signature endings, one will know from now on their 'origins' - if such an intellectual activity, the domain and hunting grounds of doubly imprisoned and foolish "intellectual intellectuals", had any urgency (certainly not the one they give to it).

Meanwhile, when reading passages such as "the dangers of transposing without critic methods of intuition, good for one specific domain", we are reminded of our own 'gentle father' (as Dante had said of Virgil).

Here are also found themes shared with his colleagues, Canguilhem or Bachelard, or even Wittgenstein, such as the dangers of metaphors and common language - their inherent vagueness and equivocal nature. (Though he himself makes abundant use of them in his colorful language.)

In one passage, Canguilhem sees reminiscences of Cavailles' war or trench warfare experiences, but has he missed the other where Cavailles writes that mathematics needed to blow up the the domain of what can be numbered?

In this article Cavailles argues for the inclusion of logic within mathematical formalism while also highlighting its limits : a summary of its rules, failed attempts, and a conclusion that is sure to make dream many more of our generations.

Cavailles' legacy - still in the process of being carved out - cannot be ignored longer. To those who made the choice of dedicating their lives to others we have a real obligation.

For they did so at the expense of their own.

They were selfless, and careless in the only way carelessness is virtuous.

Gabrielle $^{1}$ returned from Fresnes alone; Cavailles' mutilated body was dumped in a hole.

\footnotetext{
${ }^{1}$ Gabrielle Ferrieres (1901-2001), born Cavailles, sister of Jean.
} 


\title{
Mathematics and formalism
}

\author{
Jean Cavailles
}

We have found amongst the papers of Jean Cavailles the following pages, obviously meant for publication; this we say based on the great care given to its writing, leading to an exceptionally easy deciphering, and the signature at the end. Unfortunately, we cannot assign any precise date to this text. However, we think that a metaphor used by Cavailles "like a jump after being on the look out" - finds meaning in his experiences of combat. This would place it in the intermediary period between the publication of the 1938 theses and On the Logic and the Theory of Science [Sur la Logique et la Theorie de la Science], written in 1942-1943 and published since.

It is certain that, for one, the formulation 'the history of mathematics "is not a history"' establishes a continuity with the fundamental themes of "Axiomatic method and formalism" ["Methode axiomatique et formalisme"] while, on the other hand, the assertion "the development of the whole of mathematics follows a necessary rhythm" announces the closing lines of On the Logic and the Theory of Science where the dialectic of concepts is restored in all of its importance at the expense of a philosophy of conscience/consciousness [conscience], powerless in its inability to justify the course of successive unpredictable events without being arbitrary.

The last formula [formule] of this paper will no doubt raise as many problems of interpretation as the one that closes the [aforementioned] posthumous work.

Returning from one of his travels to Belgium, where he had been organizer of groups and networks of Resistance, Cavailles had communicated to us the project of Jean Lameere to resume publication of the International Review of Philosophy [Revue Internationale de Philosophie] as soon as possible following the end of this conflict whose outcome, already then, left no doubt neither for one, nor the other.

The approval given by Cavailles to this project justifies the publication inside the Revue Internationale of a study that will, once more, be a measure of how considerable the loss of this great mind of great character was for all.

G. Canguilhem 


\section{MATHEMATICS AND FORMALISM}

As soon as 1825, Gergonne distinguished between 'concrete mathematics' and formal theory of operations relating to any objects.

But, the evolution of the XIXth century would tend to the removal of the former at the benefit of the second : unexpected intersections, the uncovering of new roads [or ways] showed already, through intended comparisons, just how equivocal [multivoque] the recourse to evidence was, and, on the other hand, the dangers of transposing without critic methods of intuition, good for one specific domain (the differential treatments of finite sums and infinite sums; the non-commutative nature of the multiplication of certain complex numbers). Hence the need to unify through generalization rather than assimilation; to specify within the domain of the sensible rather than to imagine: systematization and symbolism, the two habitual medicines of the mathematician as soon as any difficulty appears, and on which novel theories are founded. Making use of it for the entire edifice, transformed into an immense system of symbols, there is nothing new to this : it is the old dream of panlogism.

It is indeed of importance to integrate logic within formalism. The interruption of symbolic chaining by reasonings made 'in the clear' would render any preceding efforts vain : one single word, one intuitive jump in thinking [of the thought], and as soon are reintroduced links to sensations and notions of limited validity.

If mathematics is, as Frege and Dedekind said, but a part of logic, the latter in turn cannot be anything else but mechanical play of symbols : propositions and reasonings are returned to well defined and precise materializations.

At its origins, we'll establish a set of few and easily recognizable symbols : parentheses, letters, etc., and some rules of usage that give them meaning : the coming together [reunion] of certain signs in an order conforming to these rules will constitute a formula.

Lastly, certain formulas - or certain schemas, which is to say formulas where blanks are left, fillable by signs belonging to predetermined categories - will be established as being fundamentally valid : they are the axioms.

Rules will enable their combination and transformation so as to enable new valid formulas : for example substitution rules that will enable to replace in an axiom some signs with others, and implication rules thanks to which - given two formulas of which the first has already been shown valid, the second written after it, with the sign $\Longrightarrow$ between the two, will constitute a valid expression, and rightfully we will be able to establish the second as valid too.

Rules governing the use of these symbols, axioms, and rules of transformation of formulas are of course not arbitrary, but chosen so as to enable the translation of the most common intuitive reasonings : this will be general logic.

(...)

But, two questions arise : Is it thus possible to engender all objects or system of objects - of historical mathematics? On the other hand, are we certain that with sufficient axiomatic rules we would we not be able 
to construct formulas rejected by it?

(...)

[As for] the first problem, we are sent back to the negative solution of Skolem. Let us suppose that all current mathematics might be inserted into our formalism : it will thus become possible to write all of its axioms one after the other (...) [But,] actual mathematics [la mathematique en acte] forces us to blow up the domain of what can be numbered, it cannot be submitted to a universal formalism. (...)

We cannot prove in an integral formalism the non-contradiction of arithmetics : such was the result obtained by Godel, in a fashion [or manner] analogous to that of Skolem.

(...)

As such the imperialism of XIXth century symbolism had concluded on a double failure. As much as Hilbert had contributed to it, he never claimed it (to be) complete.

(...)

Axiomatism, and the crisis of formalism have not been useless works. They had contributed to rigor and purity of thought through the removal of unwanted weeds [adventice]; and had enabled the establishment of unexpected relationships and kinships between distinct disciplines.

(...)

A few some [Pas mal] stairs are missing in this edifice still under construction.

(...)

The failure of the simplistic attempt to reduce all of mathematics to its poorest parent, combinatorics [le calul combinatoire], is proof enough. No need to try out a more ambitious plan, like Cantor with his theory of ensembles [set theory].

Mathematical activity is object of analysis and has an essence : but like a fragrance or a sound, it is itself.

L'activite mathematique est object d'analyse et possede une essence : mais comme une odeur ou comme un son, elle est elle-meme. 
The Journal of Symbolic Logic, Vol. 15, No. 2 (Jun., 1950).

JEAN CAVAILLES. Mathematiques et formalisme. Revue international de philosophie (Brussels), vol. 3 (1949), pp. 158-165.

A posthumous fragment containing informal reflections of a general nature about the formalization of mathematics, problems of Hilbertian proof theory (especially those of consistency and completeness), and the theorems of Godel (4183A). There is an introductory editorial note by G. Canguilhem, and at the end is added a useful bibliography of publications by and about Cavailles. (See also the dedication of the number to Cavailles, on page 157, signed by Jean Lameere.)

Alonzo Church 